\title{
Isomannide-Containing Poly(butylene 2,5-furandicarboxylate) Copolyesters via Ring Opening Polymerization
}

\author{
Juan Carlos Morales-Huerta, ${ }^{1}$ Antxon Martínez de llarduya, ${ }^{1}$ \\ Salvador León ${ }^{2}$ and Sebastián Muñoz-Guerra ${ }^{1 *}$ \\ ${ }^{1}$ Department d'Enginyeria Química, Universitat Politècnica de Catalunya, \\ ETSEIB, Diagonal 647,8028 Barcelona, Spain \\ ${ }^{2}$ Departamento de Ingeniería Química, Universidad Politécnica de Madrid, \\ ETSIIM, Gutiérrez Abascal 2, 28006 Madrid, Spain
}

\begin{abstract}
Correspondence to: S. Muñoz-Guerra (E-mail: sebastian.munoz@upc.edu) Additional Supporting Information (SI) may be found in the online version of this article.
\end{abstract}

\begin{abstract}
Cyclic oligomers of isomannide 2,5-furandicarboxylate were synthesized using the high dilution condensation method. A mixture of dimer, trimer and tetramer species largely enriched in the dimer was obtained. These cyclic oligomers were copolymerized with those made of butylene 2,5-furandicarboxylate in bulk at $220{ }^{\circ} \mathrm{C}$ by ring opening polymerization using $\mathrm{Sn}(\mathrm{Oct})_{2}$ as catalyst. A series of random poly(butylene 2,5-furandicarboxylate) copolyesters containing isomannide in a range of 5 to $50 \%$-mole and with weight-average molecular weights between 30,000 and $50,000 \mathrm{~g} \cdot \mathrm{mol}^{-1}$ were prepared. These copolyesters started to decompose above $300{ }^{\circ} \mathrm{C}$ and only those containing less than $10 \%$-mole of isomannide showed signs of crystallinity. They displayed glass-transition temperatures in the $40-100{ }^{\circ} \mathrm{C}$ range with values increasing steadily with the content in isomannide. At difference with the poly(butylene 2,5-furandicarboxylate) homopolyester that is reluctant to hydrolysis, the isomannide-containing copolyesters were noticeably degraded by water, much more rapidly when exposed to the presence of lipases.
\end{abstract}

Keywords: Bio-based polyesters, furan-based polyesters, polyfuranoates, FDCA, isohexides, isomannide, poly(butylene furanoate), ring-opening polymerization. 


\section{Introduction}

Ring Opening Polymerization (ROP) of cyclic monomers is a well-known method in polymer chemistry, in particular when the synthesis of polycondensation polymers is concerned. ${ }^{1,2}$ Despite the advantages offered by ROP (milder reaction conditions, absence of subproducts, minimization of side-reactions, etc.), conventional polycondensation continues to be the preferred preparation method for polyesters because of the high difficulty that is generally met in supplying the lactones required for the application of ROP., Nevertheless some representatives polyesters such as polylactic acid or poly(e-caprolactone) are industrially produced by $\mathrm{ROP}^{5-7}$ and the expansion of this method, although gradual, appears to be incessant. Both enthalpically and entropically driven processes are known to operate in ROP depending on the size of the lactone that is polymerized. . $^{1,2,8,9}$

Aromatic polyesters, most of them poly(phthalate)s, are invariably produced at the industrial scale by polycondensation in the melt of diols and bencendicarboxylic acids or their methyl esters. ${ }^{10-12}$ Nonetheless a diversity of cyclic oligophthalates and their ROP to linear polyesters have been reported in the scientific literature. ${ }^{1,2}$ The synthesis of these cycles using the so-called high-dilution condensation method and their ROP to poly(alkylene terephthalate)s and poly(alkylene isophthalate)s was firstly described by Brunelle et al., ${ }^{14,15}$ and later extended to other related polyesters by different authors. ${ }^{16-20}$ Recently the preparation of cyclic oligo(alkylene 2,5furandicarboxylate)s by this method has been reported, ${ }^{21,22}$ which has opened a new via towards the preparation of furane-based polyesters and copolyesters. Thus random furanoate-terephthalate ${ }^{23}$ and furanoate-succinate ${ }^{24}$ copolyesters, as well as furanoate copolyesters containing caprolactone ${ }^{25}$ have been synthesized by ROP with results comparable to those attained by melt polycondensation.

Polyfuranoates derived from 2,5-furandicarboxylic acid (FDCA) are polyesters of maximum current interest. ${ }^{26}$ Poly(ethylene 2,5-furandicarboxylate) (PEF) and poly(butylene 2,5-furandicarboxylate) (PBF) are sustainable aromatic polyesters that 
are proposed as potential substitutes of the industrial thermoplastics poly(ethylene terephthalate) (PET) and poly(butylene terephthalate) (PBT), respectively. In fact, PBF combines a bio-based character with a set of properties that compares or even surpasses those of PBT. ${ }^{27-30}$ Considerable efforts have been made however to modify its physical or/and chemical behavior, and a number of PBF copolyesters displaying novel properties may be today found in the literature. ${ }^{23-25,29}$ One usually applied approach has been to design PBF copolyesters with high $T_{\mathrm{g}}$ or/and enhanced biodegradability without detriment of the genuine sustainability of the parent homopolyester. This is really challenging since stiff monomers coming from renewable sources and suitable for polycondensation are not frequent. Bicyclic dianhydroalditols $\mathrm{s}^{31,32}$ and diacetalized alditols ${ }^{33}$ are exceptional examples of diols that could be used for such purpose.

Isomannide (Im) together with isosorbide (Is) and isoidide (Id) are 1,4:3,6 dianhydroalditols (commonly known as isohexides), a family of bicyclic diols that have attracted great attention in these last decades as new bio-based monomers for polycondensation. ${ }^{31,32}$ The high interest for isohexides arises not only from their biobased character but also from their capacity to generate high $T_{\mathrm{g}}$ polymers due to the great stiffness of the bicyclic structure. ${ }^{34,35}$ Isosorbide (1,4:3,6 dianhydrosorbitol derived from D-glucose) is by far the most widely known and used isohexide. A wide number of polycondensates containing isosorbide have been described and even some of them have achieved industrial realization. ${ }^{36-38}$ Isomannide has certain chemical advantages on isosorbide due to its more symmetrical structure but it has been much less studied because its accessibility is more difficult. Nonetheless, the only isohexide-containing cyclic oligomers suitable for ROP that have been reported in the literature ${ }^{39,40}$ are made from aliphatic dicarboxylic acids.

In this paper we wish to report on Im-containing copolyesters of poly(butylene 2,5-furandicarboxylate) prepared by ROP. Novel cyclic oligo(isomannide 2,5furandicarboxylate), $\quad c(\operatorname{ImF})_{n}$, have been synthesized and copolymerized with 
oligo(butylene 2,5-furandicarboxylate), $c(B F)_{n}$, to obtain a series of poly(butylene-coisomannide 2,5-furandicarboxylate) copolyesters, $\left(\operatorname{coPB}_{\mathrm{x}} \operatorname{Im} \mathrm{F}\right)$, with $\mathrm{Im}$ contents ranging from 0 up to $50 \%$-mole. The copolyesters are fully characterized and their thermal properties and degradability are evaluated as a function of the comonomeric composition. To our knowledge, only isosorbide has been used so far for making furanoate-based copolyesters, and conventional polycondensation was the technique invariably applied in such cases. ${ }^{41-42 .}$ Furthermore, this is the first time that aromatic polyesters containing isohexides are synthesized by ROP, and also that the thermal properties and biodegradability of PBF have been enhanced without detriment of its sustainability.

\section{Experimental}

Materials. 2,5-Furandicarboxylic acid (FDCA, 98\% purity) was purchased from Satachem and isomannide (Im, 98\%) from TCl Chemicals. Thionyl chloride $\left(\mathrm{SOCl}_{2}\right.$, 99\%), di-azabicyclo[2.2.2] octane (DABCO, 99\%), tin octoate (Sn(Oct) $2,98 \%)$ and porcine pancreas lipase were purchased from Sigma Aldrich. All solvents were of high-purity grade and used as received with the exception of tetrahydrofuran (THF) that was dried on $3 \AA$-molecular sieves and DABCO catalyst that was purified by sublimation.

Measurements. ${ }^{1} \mathrm{H}$ and ${ }^{13} \mathrm{C}$ NMR spectra were recorded on a Bruker AMX-300 spectrometer at $25{ }^{\circ} \mathrm{C}$, operating at 300.1 and $75.5 \mathrm{MHz}$, respectively. All the compounds were dissolved in deuterated chloroform $\left(\mathrm{CDCl}_{3}\right)$ or a mixture of $\mathrm{CDCl}_{3}$ and trifluoroacetic acid (TFA). The spectra were internally referenced to tetramethylsilane (TMS). About 10 and $50 \mathrm{mg}$ of sample in $1 \mathrm{~mL}$ of solvent were used for ${ }^{1} \mathrm{H}$ and ${ }^{13} \mathrm{C}$ NMR, respectively. Sixty-four scans were recorded for ${ }^{1} \mathrm{H}$ and between 1,000 and 10,000 scans for ${ }^{13} \mathrm{C}$ NMR. High performance liquid chromatography (HPLC) analyses were performed at room temperature in a Waters apparatus equipped with a UV detector of Applied Biosystems operating at $254 \mathrm{~nm}$ wavelength, 
and a Scharlau Science column (Si60, $5 \mu \mathrm{m} ; 250$ x $4.6 \mathrm{~mm}$ ). Cyclic oligomers (1 mg) were dissolved in chloroform $(1 \mathrm{~mL})$ and eluted with hexane/1,4-dioxane 70/30 (v/v) at a flow rate of $1.0 \mathrm{~mL} \cdot \mathrm{min}^{-1}$. Molecular weight analyses of polymers were performed by GPC on a Waters equipment provided with RI and UV detectors. $100 \mu \mathrm{L}$ of $0.1 \%$ (w/v) sample solution was injected and chromatographed using 1,1,1,3,3.3-hexafluoro2-propanol (HFIP) as mobile phase with a flow of $0.5 \mathrm{~mL} \cdot \mathrm{min}^{-1}$. HR5E and HR2 Waters linear Styragel columns $\left(7.8 \mathrm{~mm} \times 300 \mathrm{~mm}\right.$, pore size $\left.10^{3}-10^{4} \AA\right)$ packed with crosslinked polystyrene and protected with a precolumn were used. Average molar masses and dispersities were calculated against PMMA standards. Matrix-assisted laser desorption/ionization time of flight (MALDI-TOF) mass spectra were recorded in a 4700 Proteomics Analyzer instrument (Applied Biosystems) of the Proteomics Platform of Barcelona Science Park, University of Barcelona. Spectra acquisition was performed in the MS reflector positive-ion mode. About $0.1 \mathrm{mg}$ of sample was dissolved in $50 \mu \mathrm{L}$ of $\mathrm{DCM}$ and $2 \mu \mathrm{L}$ of this solution were mixed with an equal volume of an anthracene solution in dichloromethane (DCM) $\left(10 \mathrm{mg} \cdot \mathrm{mL}^{-1}\right)$, and the mixture left to evaporate to dryness onto the stainless steel plate of the analyser. The residue was then covered with $2 \mu \mathrm{L}$ of a solution of 2,5-dihydroxibenzoic acid in acetonitrile/ $\mathrm{H}_{2} \mathrm{O}(1 / 1)$ containing $0.1 \%$ TFA, and the mixture was left to dry prior to exposition to the laser beam.

Thermogravimetric analysis (TGA) of polymers was performed on a MettlerToledo TGA/DSC 1 Star System under a nitrogen flow of $20 \mathrm{~mL} \cdot \mathrm{min}^{-1}$ at a heating rate of $10^{\circ} \mathrm{C} \cdot \mathrm{min}^{-1}$ and within a temperature range of $30-600{ }^{\circ} \mathrm{C}$. The non-destructive thermal behaviour was examined by differential scanning calorimetry (DSC) within the $30-200{ }^{\circ} \mathrm{C}$ range using a Perking-Elmer Pyris apparatus. Thermograms were obtained from 4-6 $\mathrm{mg}$ samples at heating and cooling rates of $10^{\circ} \mathrm{C} \cdot \mathrm{min}^{-1}$ under a nitrogen flow of $20 \mathrm{~mL} \cdot \mathrm{min}^{-1}$. Indium and zinc were used as standards for temperature and enthalpy calibration. The glass transition temperature $\left(T_{g}\right)$ was taken 
as the inflection point of the heating traces recorded at $20^{\circ} \mathrm{C} \cdot \mathrm{min}^{-1}$ from meltquenched samples, and the melting temperature $\left(T_{m}\right)$ was taken as the maximum of the endothermic peak appearing on the heating traces recorded from samples crystallized from the melt.

X-Ray diffraction patterns from powdered samples coming directly from synthesis were recorded on a PANalytical X'Pert PRO MPD $\theta / \theta$ diffractometer using the $\mathrm{CuK}_{\alpha}$ radiation of wavelength $0.1542 \mathrm{~nm}$. Optical micrographs were taken using an Olimpus BX51 polarizing optical microscope with a Linkam THMS 600 stage attached. For observation, $10 \mathrm{mg}$ of sample were dissolved in $1 \mathrm{~mL}$ of HFIP for PBF or chloroform for copolyesters, and $0.2 \mathrm{~mL}$ aliquots of these solutions were slowly evaporated on a glass slide.

Cyclic oligomers synthesis. Cyclic oligomers $c(B F)_{n}$ were synthesized applying the high dilution condensation method (HDC) previously reported by us. $^{22}$ Cyclic oligomers $c(\operatorname{ImF})_{n}$ were synthesized applying the same method. Briefly,Error! Bookmark not defined. a three-necked round bottom flask was charged with $250 \mathrm{~mL}$ of THF and cooled to $0^{\circ} \mathrm{C}$, and then $12.5 \mathrm{mmol}(1.40 \mathrm{~g})$ of DABCO were added under stirring. $5 \mathrm{mmol}(0.96 \mathrm{~g})$ of $\mathrm{FDCA}-\mathrm{Cl}_{2}$ and $5 \mathrm{mmol}(0.73 \mathrm{~g})$ of isomannide in $10 \mathrm{~mL}$ of THF were drop-wise added simultaneously for 40 min using two addition funnels in order to maintain the reagents equimolarity in the reaction mixture. The reaction was finished by adding $1 \mathrm{~mL}$ of water followed by $5 \mathrm{~mL}$ of $1 \mathrm{M} \mathrm{HCl}$, and after stirring for 5 min, it was diluted with $\mathrm{DCM}$ and filtered. The filtrate was washed with $0.1 \mathrm{M} \mathrm{HCl}$ and water, dried on $\mathrm{MgSO}_{4}$, and evaporated to dryness to render a mixture of linear and cyclic oligomers. Linear oligomers were removed by flash chromatography through a short column of silica gel using a cold mixture of DCM/diethyl ether 90/10 (v/v) as eluent. Yield: $60 \% . c(\operatorname{ImF})_{n}:{ }^{1} \mathrm{H}$ NMR ( $\left.\delta \mathrm{ppm}, \mathrm{CDCl}_{3}, 300 \mathrm{MHz}\right): 7.34(1 \mathrm{~s}, 2 \mathrm{H}), 5.39$ $(\mathrm{m}, 2 \mathrm{H}), 4.91(\mathrm{~m}, 2 \mathrm{H}), 4.35(\mathrm{~m}, 2 \mathrm{H}) ; 3.99(\mathrm{~m}, 2 \mathrm{H}) ;{ }^{13} \mathrm{C} \mathrm{NMR}\left(\delta \mathrm{ppm}, \mathrm{CDCl}_{3}, 75.5\right.$ 
$\mathrm{MHz}): 157.2,146.4,146.3,146.0,119.6,119.4,80.7,74.5,74.4,73.9,71.2,71.1$, 70.9 .

Polymer synthesis. Copolymerization of $c(\mathrm{BF})_{\mathrm{n}}$ and $c(\mathrm{ImF})_{\mathrm{n}}$ was performed in bulk following the procedure previously reported by $u$ s. $^{23}$ Briefly, mixtures of $c(\mathrm{BF})_{\mathrm{n}}$ and $c(\operatorname{ImF})_{\mathrm{n}}$ with the selected molar compositions were placed in a three necked round bottom flask provided with a $\mathrm{N}_{2}$ flow and heated at $220^{\circ} \mathrm{C}$. Then $\mathrm{Sn}(\mathrm{Oct})_{2}(0.5 \%$-mole $)$ was added to the molten mass and the reaction was left to proceed for $6 \mathrm{~h}$. The reaction mixture was then cooled down to room temperature, diluted with $\mathrm{CHCl}_{3}$, and precipitated with diethyl ether. The precipitated sample was analyzed by NMR.

Hydrolytic and enzymatic degradation. Hydrolytic degradation and biodegradation studies were made on PBF and PImF homopolyesters, and coPB ${ }_{50} / m_{50} F$, and $\mathrm{coPB}_{70} \mathrm{Im}_{30} \mathrm{~F}$ copolyesters. Films of these polymers with a thickness of $\sim 200 \mu \mathrm{m}$ were prepared by casting from either HFIP or chloroform solution at a polymer concentration of $100 \mathrm{~g} \cdot \mathrm{L}^{-1}$. The films were cut into $10 \mathrm{~mm}$-diameter, $20-30 \mathrm{mg}$-weight disks and dried under vacuum to constant weight. For hydrolytic degradation, samples were immersed in vials containing $10 \mathrm{~mL}$ of either citric acid buffer, $\mathrm{pH} 2.0$ or sodium phosphate buffer, $\mathrm{pH} 7.4$ at $37^{\circ} \mathrm{C}$. Enzymatic degradation assays were carried out at $37^{\circ} \mathrm{C}$ in $\mathrm{pH} 7.4$ buffered sodium phosphate solution with $10 \mathrm{mg}$ of porcine pancreas lipase added. In this case the buffered solution was replaced every $72 \mathrm{~h}$ in order to maintain the enzyme activity. In both cases, disks were withdrawn from the incubation medium at scheduled periods of time, washed carefully with distilled water, dried to constant weight, and finally analysed by GPC.

\section{Results and discussion}

The strategy followed to synthesize the cyclic oligoesters $c(B F)_{n}$, and $c(\operatorname{Im})_{n}$, and to polymerize them for producing the copolyesters $\operatorname{coPB}_{\mathrm{x}} \mathrm{Im}_{\mathrm{y}} \mathrm{F}$ is depicted in Scheme 1. 
Scheme 1. Synthetic route to poly(butylene-co-isomannide 2,5 furandicarboxylate) copolyesters.

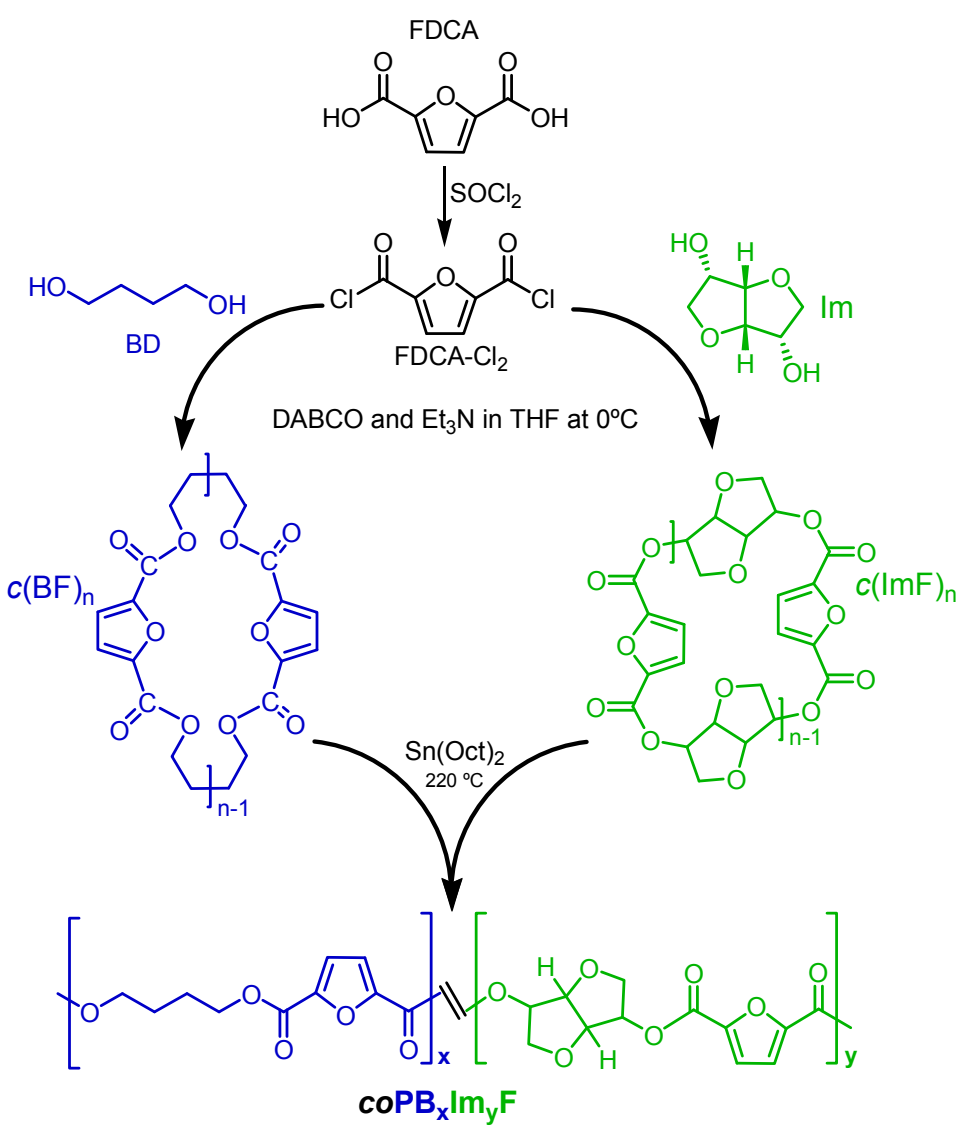

Cyclic oligomers. $c(B F)_{n}$ were synthesized as described in several works recently reported by us. ${ }^{22,25}$ following the high dilution (HDC) technique assisted by the organic catalyst DABCO. Characterization details of these cyclic oligomers are provided in the SI file (Figure S1). The same technique was then applied to the synthesis of cyclic oligo(isomannide 2,5-furandicarboxylate) $c(\operatorname{ImF})_{n}$, which are described in this paper for the first time. The NMR of the crude reaction product revealed that, in analogy with that happens with $c(B F)_{n}$, it was a mixture of cyclic oligomers of different sizes contaminated by a significant amount of linear species (Figure S2). After removing the linear oligomers by flash chromatography, the eluted sample was analyzed by NMR, 
Maldi-Tof and HPLC (Figure 1) which demonstrated that this fraction consisted mainly of dimer (85\%) accompanied by minor amounts of trimer and tetramer $(10 \%$ and $5 \%$,

a)

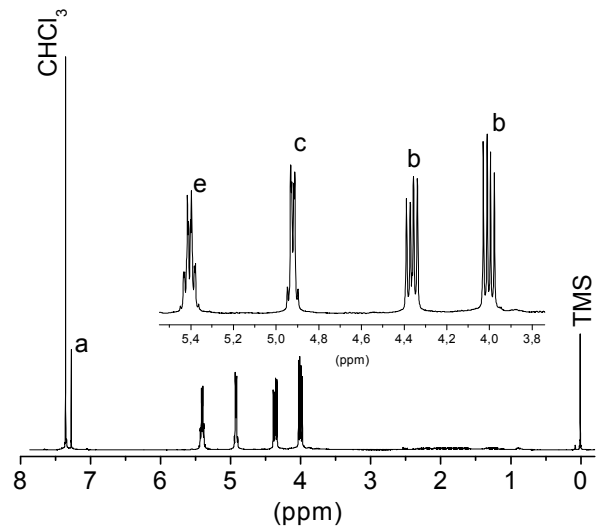

b)

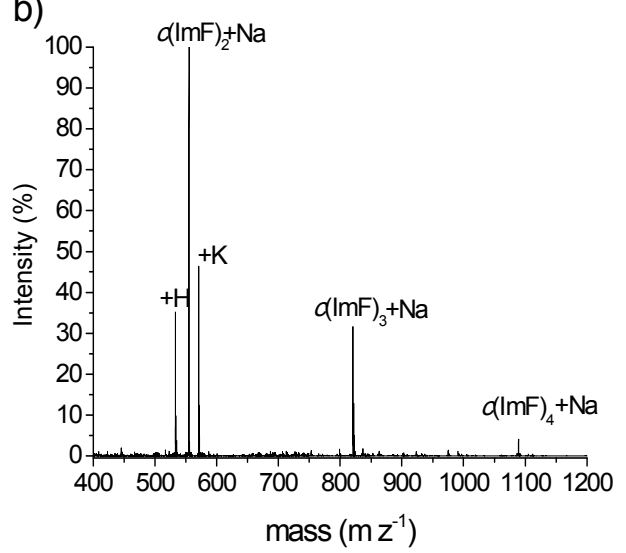

c) $\quad(\operatorname{lmF})_{2}$

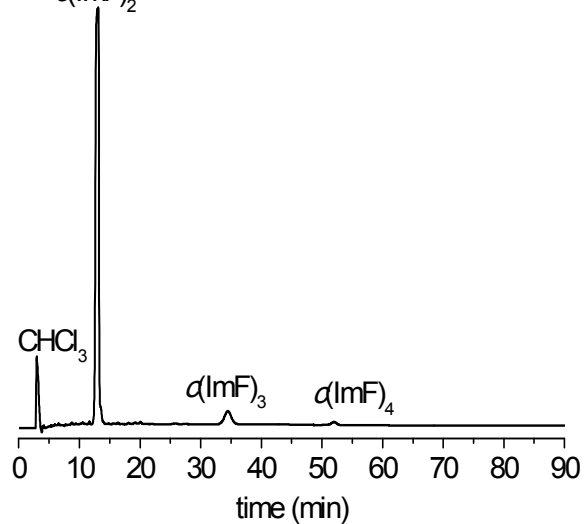

Figure 1. a) ${ }^{1} \mathrm{H}$ NMR, b) MALDI-ToF, and c) HPLC of $c(\mathrm{ImF})_{\mathrm{n}}$ after purification.

respectively). The thermal analysis of $c(\operatorname{ImF})_{n}$ by TGA showed that these cycles are resistant to heat up to temperatures around $350^{\circ} \mathrm{C}$, and the DSC analysis revealed that they are crystalline with melting point at $160{ }^{\circ} \mathrm{C}$ (Figure 2). The most relevant

Table 1. Cyclic Oligomers Used for the ROP Synthesis of Im-Containing Copolyesters.

\begin{tabular}{llccccc}
\hline $\begin{array}{l}\text { Cyclic } \\
\text { oligomer }\end{array}$ & Precursors & Yield $^{\mathrm{a}}$ & Composition $^{\mathrm{b}}$ & \multicolumn{3}{c}{ Thermal Properties $^{\mathrm{c}}$} \\
\cline { 5 - 7 } & & $(\%)$ & $n=2,3,4$ & ${ }^{\circ} T_{d}\left({ }^{\circ} \mathrm{C}\right)$ & ${ }^{\max } T_{d}\left({ }^{\circ} \mathrm{C}\right)$ & $T_{m}\left({ }^{\circ} \mathrm{C}\right)$ \\
\hline $\mathrm{C}(\mathrm{BF})_{\mathrm{n}}$ & $\mathrm{FDCA}_{\mathrm{n} C l_{2}}+\mathrm{BD}$ & 67 & $62 / 30 / 8$ & 240 & 378 & 147 \\
$C(\mathrm{ImF})_{\mathrm{n}}$ & $\mathrm{FDCA}-\mathrm{Cl}_{2}+\mathrm{Im}$ & 62 & $85 / 10 / 5$ & 350 & 410 & 161 \\
\hline
\end{tabular}

${ }^{a}$ Yields after removing the linear species by flash chromatography.

${ }^{\mathrm{b}}$ Molar ratio of cycle species determined by HPLC.

${ }^{\mathrm{c}}$ Determined by TGA and DSC. ${ }^{\circ} T_{d}$ is the onset temperature determined for a weight loss of $5 \%,{ }^{\max } T_{d}$ is the temperature for maximum decomposition rate, and $T_{\mathrm{m}}$ is the melting temperature. 
characteristics of these cycles compared with those of $c(\mathrm{BF})_{\mathrm{n}}$ are collected in Table 1.

a)

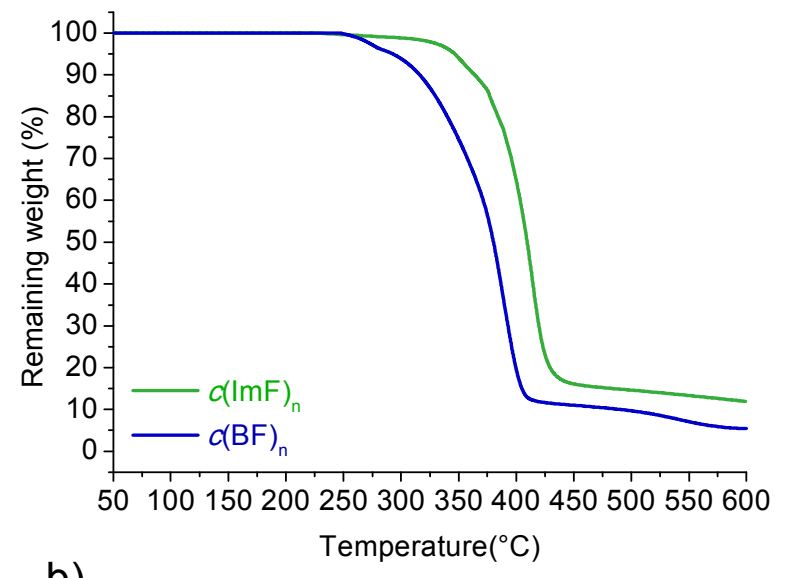

b)

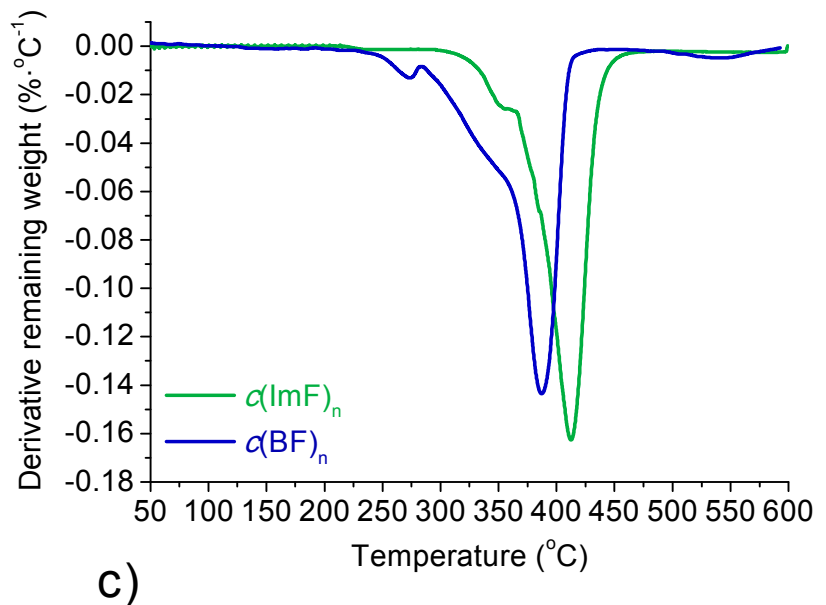

C)

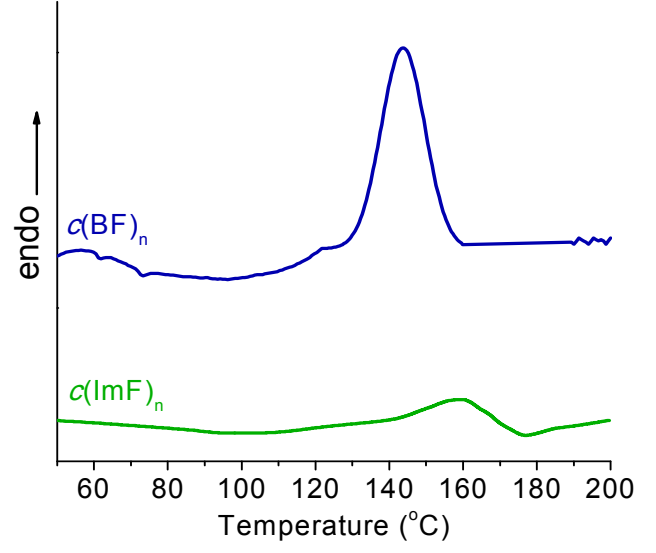

Figure 2. a) TGA (a and b) and DSC (c) of $c(B F)_{n}$ and $c(\operatorname{ImF})_{n}$. 
It is noteworthy to report that a series of experiments similar to those carried out for the synthesis of $c(\operatorname{ImF})_{n}$ were made using isosorbide, i.e. the isohexide derived from glucose, with the purpose of generating its corresponding cyclic oligoesters. Unfortunately, all the attempts were unsuccessful and apparently only linear oligomers were obtained according to the NMR analysis (Figure S3). The unfavorable relative spatial orientation of the two reactive hydroxyl groups in Is (exo and endo) compared to the two endo positions occupied by the two hydroxyls in Im could be invoked to be responsible for the different behavior observed. An exploratory study on the energy of the cyclic oligofuranoates of the three known isohexides (Is, Im and Id) was comparatively performed by molecular simulations. The results clearly revealed that cyclic oligomers made of Is are less stable than those made of Im (Figure S4), which is fully consistent with the experimental results reached in the attempts of cyclization carried out with isomannide and isosorbide. Simulation results also indicated a relative high energy for the cyclic oligofuranoates containing isoidide, which leads to predict that cyclization involving this diol will be hampered too. Isoidide has the two hydroxyl groups in exo position, which is very favorable for reactivity but not for cyclization due to their opposite orientation in the space.

Synthesis of copolyesters. Mixtures of $c(\mathrm{BF})_{\mathrm{n}}$ and $c(\mathrm{ImF})_{\mathrm{n}}$ covering the ratio range of 95/5 to $50 / 50$ were copolymerized by ROP in bulk using tin 2-ethylhexanoate as catalyst to produce the $\mathrm{coPB}_{\mathrm{x}} \mathrm{Im} \mathrm{m}_{\mathrm{y}} \mathrm{F}$ copolyesters series. The homopolyesters PBF and PImF to be used as references in characterization and properties studies were prepared by this method too. The reaction temperature was fixed by taken into account the meltability of the cyclic fractions and the resulting polymers, as well as its effect on reaction kinetics. To assess this variable, a mixture of $c(\mathrm{BF})_{\mathrm{n}}$ and $c(\operatorname{ImF})_{\mathrm{n}}$ with a $60 / 40$ molar ratio was made to react at 200,220 and $230^{\circ} \mathrm{C}$, and aliquots of the reaction mixture were withdrawn at scheduled times and the molecular weight of the copolyester formed up to that instant was estimated by GPC. Results are plotted in 
Figure $3 a$ to show the positive effect of temperature on conversion upon raising it from 200 to $220^{\circ} \mathrm{C}$ whereas not significant change seems to happen after further increasing. According to these results and since the $c(B F)_{n}$ cycles started to decompose around $240{ }^{\circ} \mathrm{C}$, it was advisable to fix the reaction temperature at $220^{\circ} \mathrm{C}$ for the ROP of the whole series. To complement this study, the evolution of $M_{\mathrm{w}}$ with time in the ROP at $220{ }^{\circ} \mathrm{C}$ of $c(\mathrm{BF})_{\mathrm{n}} / c(\mathrm{ImF})_{\mathrm{n}}$ mixtures differing in composition was followed by using the same methodology as before, and results obtained therefrom are shown in Figure $3 b$.

a)

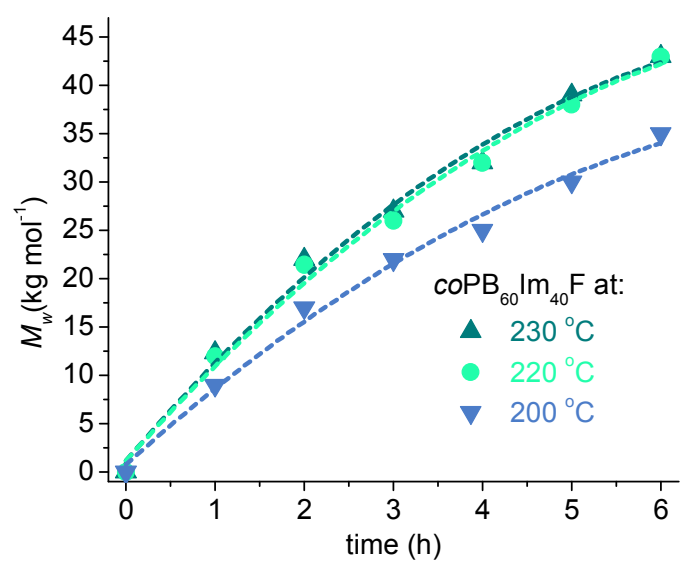

b)

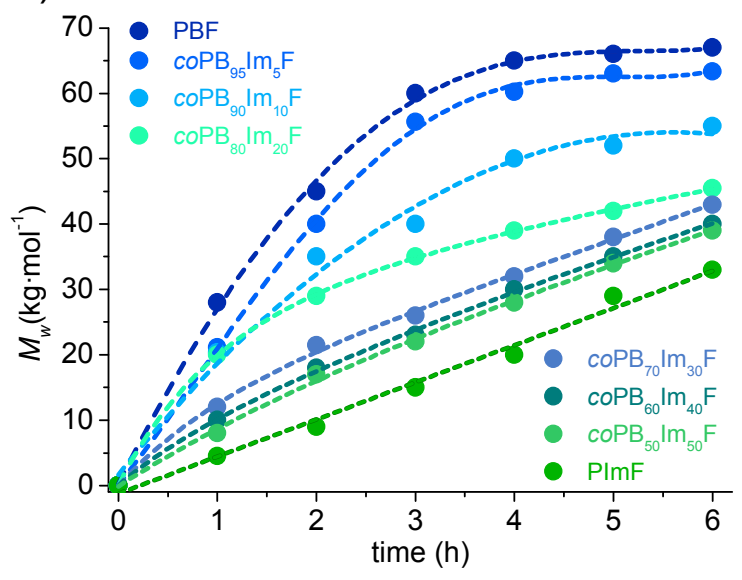

Figure 3. Plots of the evolution of $\mathrm{Mw}$ of the resulting copolyesters ${ }^{\circ} \mathrm{PB} \mathrm{B}_{\mathrm{x}} \mid \mathrm{m}_{\mathrm{y}} \mathrm{F}$ against reaction time. a) ${ }^{\circ o P B}{ }_{60} I_{40} F$ at different temperatures. b) ${ }^{\circ} \mathrm{PBB}_{\mathrm{x}} \mathrm{Im}_{\mathrm{y}} \mathrm{F}$ with different compositions.

The $M_{\mathrm{w}} v s$ time plots showed that the $M_{w}$ of the copolyesters decreased steadily with the content in $\mathrm{ImF}$ which brings out the less reactivity of the $c(\mathrm{ImF})_{\mathrm{n}}$ cycles compared to the $c(B F)_{n}$ in the ROP of their mixtures. Nevertheless, all the copolyesters could be obtained in yields and with molecular weights high enough as to validate successfully the suitability of the applied methodology in the synthesis of $c 0 P B_{x} I_{y} F$.

Yields, molecular weights and compositions of the whole $c o P B_{x} \operatorname{Im}_{y} F$ series are collected in Table 2. Yields were above $80 \%$ in all cases with losses being ascribable to the low molecular species that could not be recovered in the precipitation treatment 
to which the final reaction product is subjected. $M_{\mathrm{w}}$ of copolyesters are roughly in the $\sim 40,000-60,000 \mathrm{~g} \cdot \mathrm{mol}^{-1}$ range, and the homopolyesters PBF and PImF were obtained with $65,000 \mathrm{~g} \cdot \mathrm{mol}^{-1}$ and $28,000 \mathrm{~g} \cdot \mathrm{mol}^{-1}$ respectively, which is according to the trend observed for the copolyesters series. $\Theta$ values are between 1.5 and 2.0 which is a range of molar dispersity values according to expectations, in particular if transesterification reactions took place during ROP, a possibility that cannot be neglected given the high temperature used for reaction. The constitution of the polymers was ascertained by ${ }^{1} \mathrm{H}$ and ${ }^{13} \mathrm{C}$ NMR spectroscopy, and the spectra recorded from $\mathrm{coPB}_{60} \mathrm{Im}_{40} \mathrm{~F}$ with indication of all peak assignments are depicted in Figure 4. The spectra of the whole series are included in the SI file (Figure S5). The quantitative analysis of the ${ }^{1} \mathrm{H}$ NMR spectra based on the integration of group specific signals provided an accurate estimation of the copolymer composition in BF (butylene furanoate) and ImF (isomannide furanoate) units. As it is seen in Table 2, differences in Im contents between the feed and its generated copolyester are kept below $5 \%$ which is a small value perfectly attributable to uncontrolled experimental causes.

Table 2. Yield, Composition, Molecular Weight, and Microstructure of $\operatorname{coPB}_{\mathrm{x}} \mathrm{Im} \mathrm{m}_{\mathrm{y}} \mathrm{F}$.

\begin{tabular}{|c|c|c|c|c|c|c|c|c|c|c|c|}
\hline \multirow[t]{2}{*}{ Polyester } & \multirow[t]{2}{*}{$\begin{array}{c}\text { Yield } \\
(\%)\end{array}$} & \multicolumn{2}{|c|}{$\begin{array}{c}\text { Composition }^{a} \\
\text { x(BF/y(ImF) } \\
\text { (mole/mole) }\end{array}$} & \multicolumn{2}{|c|}{$\begin{array}{l}\text { Molecular } \\
\text { weight }^{\mathrm{b}}\end{array}$} & \multicolumn{6}{|c|}{ Microstructure $^{c}$} \\
\hline & & Feed & Copol & $\begin{array}{c}M_{w} \\
\left(g \cdot \mathrm{mol}^{-1}\right)\end{array}$ & $\boldsymbol{\theta}$ & BB & $\begin{array}{l}\text { BIm } \\
\text { ImB }\end{array}$ & Imlm & $n_{\mathrm{BF}}$ & $n_{\mathrm{ImF}}$ & $R$ \\
\hline PBF & 95 & 100 & 0 & 65,000 & 1.8 & - & & - & - & - & \\
\hline $\mathrm{PB}_{95} \mathrm{Im}_{5} \mathrm{~F}$ & 93 & $95 / 5$ & $96 / 4$ & 63,000 & 1.6 & 91.5 & 8.5 & 0 & 22.4 & 1.00 & 1.04 \\
\hline $\mathrm{PB}_{90} \mathrm{Im}_{10} \mathrm{~F}$ & 90 & $90 / 10$ & $92 / 8$ & 55,000 & 1.9 & 80.4 & 18 & 1.6 & 9.9 & 1.18 & 0.95 \\
\hline $\mathrm{PB}_{80} \mathrm{Im}_{20} \mathrm{~F}$ & 85 & $80 / 20$ & $80 / 20$ & 45,000 & 1.9 & 66.3 & 28.5 & 5.2 & 5.7 & 1.37 & 0.91 \\
\hline $\mathrm{PB}_{70} \mathrm{Im}_{30} \mathrm{~F}$ & 85 & $70 / 30$ & $66 / 34$ & 43,000 & 1.4 & 54.9 & 35.4 & 9.7 & 4.1 & 1.55 & 0.89 \\
\hline $\mathrm{PB}_{60} \mathrm{Im}_{40} \mathrm{~F}$ & 82 & $60 / 40$ & $58 / 42$ & 40,000 & 1.8 & 46.8 & 33.5 & 19.7 & 3.8 & 2.17 & 0.76 \\
\hline $\mathrm{PB}_{50} \mathrm{Im}_{50} \mathrm{~F}$ & 82 & $50 / 50$ & $55 / 45$ & 39,000 & 2.0 & 37.2 & 37.0 & 25.8 & 3.0 & 2.39 & 0.75 \\
\hline PImF & 80 & 0 & 100 & 28,000 & 1.9 & - & - & - & - & - & - \\
\hline
\end{tabular}



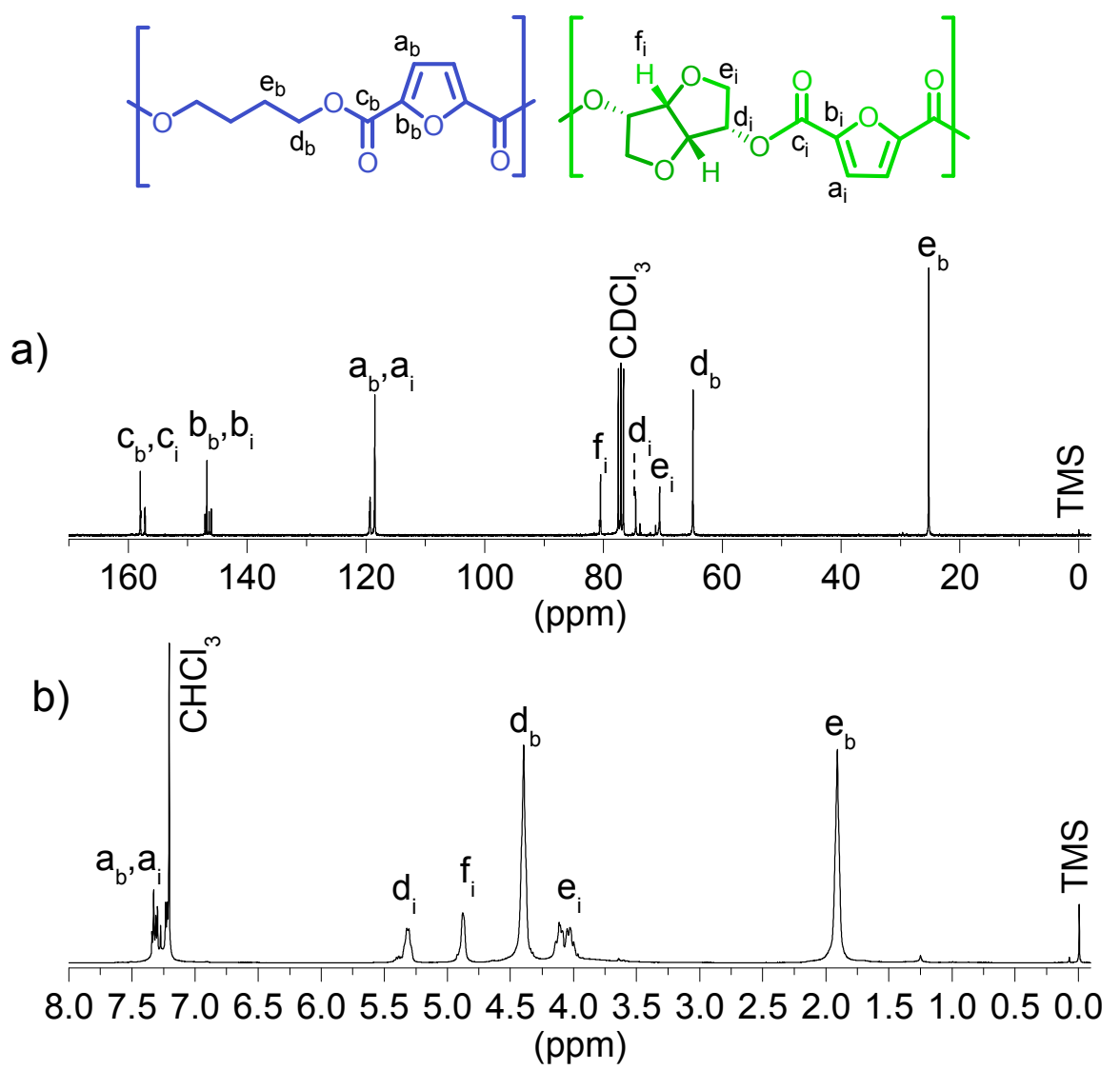

Figure 4. ${ }^{13} \mathrm{C}$ (top) and ${ }^{1} \mathrm{H}$ (bottom) NMR of $\operatorname{coPB}_{60} \mathrm{Im}_{40} \mathrm{~F}$.

The elucidation of the microstructure of the copolyesters was made by ${ }^{13} \mathrm{C}$ NMR analysis using the $145.5-147.5$ signal arising from the non-protonated aromatic carbon of the furanoate unit that is sensitive to dyads. In consequence the signal appears split into four peaks (Figure 5) corresponding to the feasible dyads BB, ImIm, BIm/lmB. Peak areas were used to calculate, according to the procedure reported by Randall, ${ }^{43}$ the number-average sequence lengths $(n)$ and the degree of randomness $(R)$ for each composition. $n$ and $R$ values are listed Table 2 indicating that a nearly statistical distribution of $\mathrm{BF}$ and $\mathrm{Im}$ is present in the $\operatorname{coPB}_{\mathrm{x}} \mathrm{Im}_{\mathrm{y}} \mathrm{F}$ copolyesters with a random degree that decreases as the content of the copolyester in isomannide increases. 

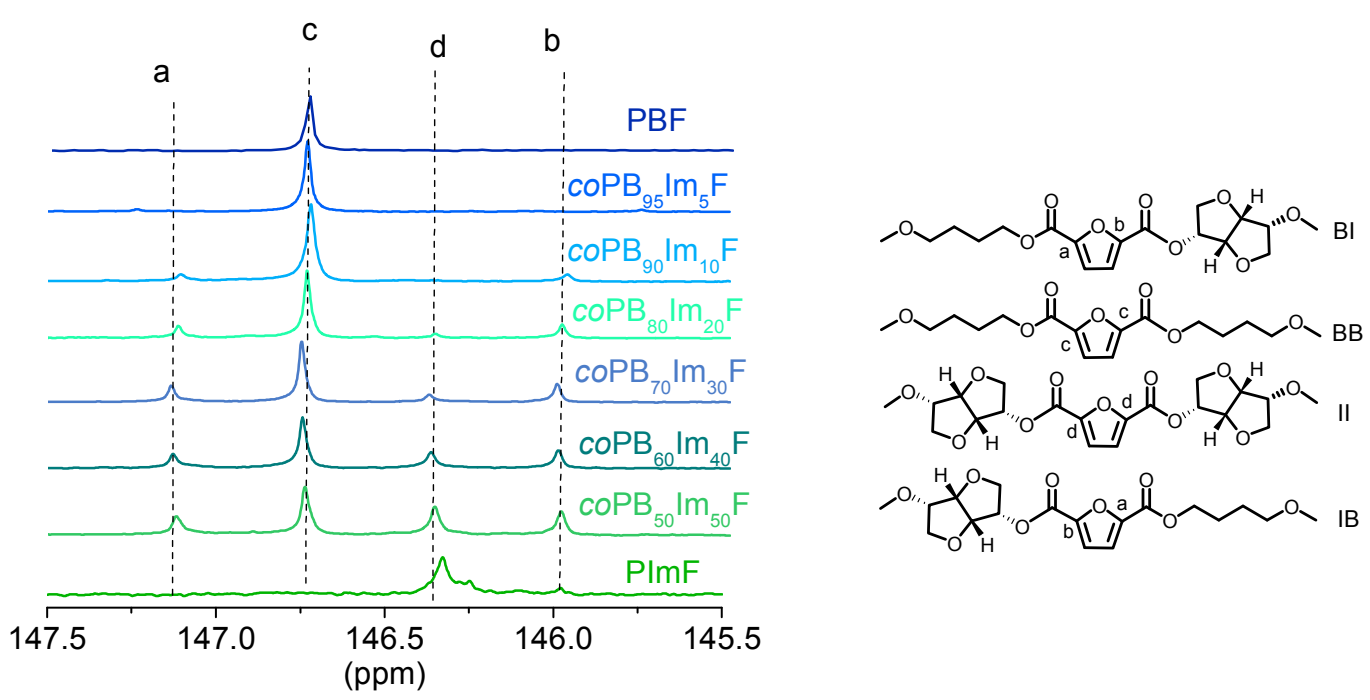<smiles>COCCCCOC(=O)c1ccc(C(=O)OCCCCCOC(=O)c2ccccc2)o1</smiles>

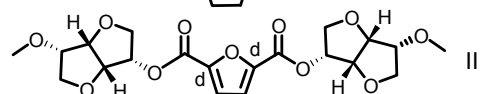

Figure 5. ${ }^{13} \mathrm{C}$ NMR signals used for microstructure analysis of $c o P B_{x} I m_{y} F$ with assignments of the carbons for the different dyads.

\section{Thermal properties}

The thermal properties of the $\mathrm{COPB}_{\mathrm{x}} \mathrm{Im} \mathrm{m}_{\mathrm{y}} \mathrm{F}$ copolyesters were analyzed by DSC and TGA, and data collected in these analyses are gathered in Table 3.

The thermogravimetric traces of the copolyesters recorded under an inert atmosphere over the 50/600 range, are depicted in Figure 6a and a representative selection of their derivative curves are shown in Figure 6b. PBF and PImF homopolyesters started to decompose around $360{ }^{\circ} \mathrm{C}$ and $325{ }^{\circ} \mathrm{C}$, respectively,

Table 3. Thermal Properties of $\mathrm{coPB}_{\mathrm{x}} \mathrm{ImF}_{\mathrm{y}}$ Copolyesters Prepared via ROP.

\begin{tabular}{|c|c|c|c|c|c|c|c|c|c|c|c|c|}
\hline \multirow[t]{3}{*}{ Copolyester } & \multirow{2}{*}{\multicolumn{3}{|c|}{ TGA }} & \multicolumn{5}{|c|}{ DSC } & \multicolumn{4}{|c|}{ Crystallization kinetics } \\
\hline & & & & \multirow[b]{2}{*}{$\begin{array}{c}T_{g} \\
\left({ }^{\circ} \mathrm{C}\right) \\
\end{array}$} & \multicolumn{2}{|c|}{$\begin{array}{c}\text { First } \\
\text { heating }\end{array}$} & \multicolumn{2}{|c|}{$\begin{array}{l}\text { Second } \\
\text { heating }\end{array}$} & \multirow[b]{2}{*}{$\begin{array}{c}T_{c} \\
\left({ }^{\circ} \mathrm{C}\right)\end{array}$} & \multirow[b]{2}{*}{$n$} & \multirow[b]{2}{*}{ InK } & \multirow[b]{2}{*}{$\begin{array}{c}t_{1 / 2} \\
(\mathrm{~min})\end{array}$} \\
\hline & $\begin{array}{l}{ }^{\circ} T_{d}^{a} \\
\left({ }^{\circ} \mathrm{C}\right)\end{array}$ & $\begin{array}{l}{ }^{\max } T_{d} \\
\left({ }^{\circ} \mathrm{C}\right)\end{array}$ & $\begin{array}{l}R_{w} \\
(\%)\end{array}$ & & $\begin{array}{c}T_{m} \\
\left({ }^{\circ} \mathrm{C}\right)\end{array}$ & $\begin{array}{c}\Delta H_{m} \\
\left(\mathrm{~J} \cdot \mathrm{mol}^{-1}\right)\end{array}$ & $\begin{array}{c}T_{m} \\
\left({ }^{\circ} \mathrm{C}\right)\end{array}$ & $\begin{array}{c}\Delta H_{m} \\
\left(\mathrm{~J} \cdot \mathrm{mol}^{-1}\right)\end{array}$ & & & & \\
\hline PBF & 360 & 400 & 6 & 42 & 172 & 35 & 172 & 35 & 146 & 2.07 & -4.46 & 7.0 \\
\hline $\mathrm{coPB}_{95} \mathrm{Im}_{5} \mathrm{~F}$ & 344 & 390 & 6 & 45 & 169 & 30 & 166 & 28 & 146 & 2.49 & -6.89 & 13.4 \\
\hline $\mathrm{coPB}_{90} \mathrm{Im}_{10} \mathrm{~F}$ & 329 & 390 & 8 & 47 & 160 & 12 & 156 & 7 & - & - & - & - \\
\hline $\mathrm{coPB}_{80} \mathrm{Im}_{20} \mathrm{~F}$ & 334 & 388 & 8 & 56 & - & - & - & - & - & - & - & - \\
\hline $\mathrm{coPB}_{70} \mathrm{Im}_{30} \mathrm{~F}$ & 330 & 390 & 9 & 66 & - & - & - & - & - & - & - & - \\
\hline $\mathrm{coPB}_{60} \mathrm{Im}_{40} \mathrm{~F}$ & 330 & 390 & 9 & 80 & - & - & - & - & - & - & - & - \\
\hline $\mathrm{coPB}_{50} \mathrm{Im}_{50} \mathrm{~F}$ & 362 & 403 & 5 & 97 & - & - & - & - & - & - & - & - \\
\hline PImF & 325 & 376 & 9 & 189 & - & - & - & - & - & - & - & - \\
\hline
\end{tabular}

${ }^{\mathrm{a}}$ Onset temperature measured for $5 \%$ of weight loss.

${ }^{\mathrm{b}}$ Avrami parameters determined from isothermal crystallization at de indicated $T_{\mathrm{c}}$. 
whereas the $c o \mathrm{~PB}_{\mathrm{x}} \mathrm{Im} \mathrm{F}$ copolyesters did it at intermediate values but without following a recognizable trend. Nevertheless ${ }^{\circ} T_{d, 5 \%}$ is far above $300{ }^{\circ} \mathrm{C}$ for whichever composition, which is a clear indication of the good thermal stability of these copolyesters. A similar pattern is observed for the temperature at which maximum rate decomposition takes place although in this case this temperature is much less fluctuant along the series. In fact, ${ }^{\max } T_{d}$ of copolyesters is confined in the $\sim 390-400{ }^{\circ} \mathrm{C}$, which are values very close to that of PBF but clearly above the $376{ }^{\circ} \mathrm{C}$ shown by the PImF homopolyester. It is remarkable that decomposition of all the polyesters takes place through one single step and at a rate that largely depends on the content in Im units. Residual weights after heating at $600{ }^{\circ} \mathrm{C}$ oscillated between $5 \%$ and $10 \%$ of the initial sample weight without showing apparent interrelation with the polyester composition.

a)

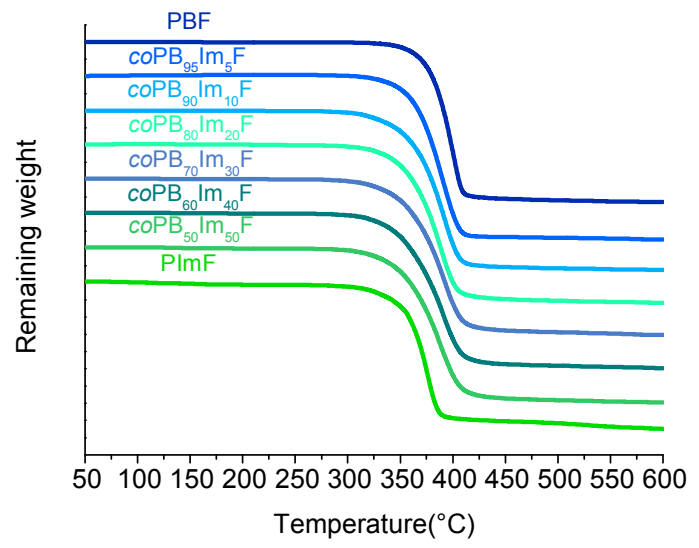

b)

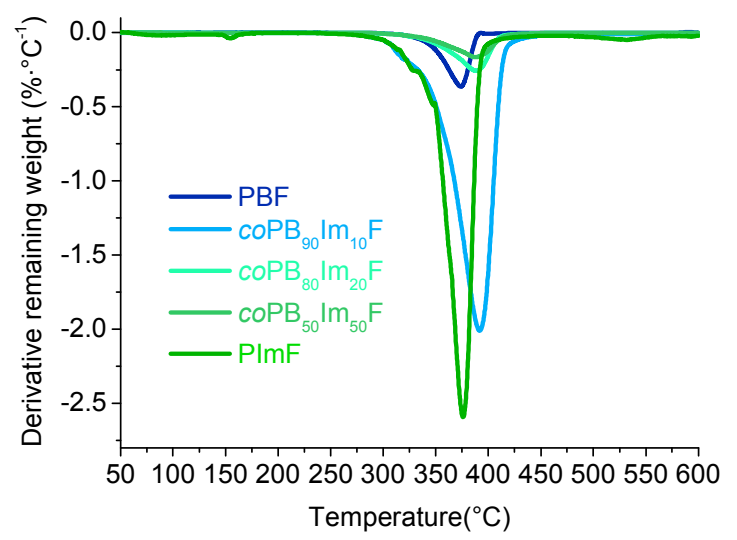

Figure 6. TGA traces of $\mathrm{COPB}_{\mathrm{x}} \mathrm{Im}_{\mathrm{y}} \mathrm{F}(\mathrm{a})$ and a selection of their derivative curves (b).

The DSC traces of coPB $_{x} \mathrm{Im}_{\mathrm{y}} \mathrm{F}$ together with those of PBF and PImF homopolyesters, recording at heating and cooling over the $0-200{ }^{\circ} \mathrm{C}$ range, are depicted in Figure 7. Only PBF and copolyesters containing as maximum $10 \%$ of $\mathrm{Im}$ were found to display thermal changes indicative of melting or crystallization. Furthermore, only $\mathrm{coPB}_{95} \mathrm{Im}_{5} \mathrm{~F}$ was able to crystallize clearly from the melt whereas an extremely weak broad crystallization exotherm was hardly seen on the cooling trace of 
$\operatorname{coPB}_{90} \mathrm{Im}_{10} \mathrm{~F}$. As expected, both melting temperature and enthalpy decreased with the content in isomannide. It can be said therefore that $c o P B_{x} \operatorname{Im}_{y} F$ copolyesters are essentially amorphous polymers as it is also the case for PImF homopolyester, a feature that had been earlier reported by Okada et al. ${ }^{36}$ These results bring into evidence the strong repressing effect that the insertion of Im units into the PBF chain exerts on the genuine crystallinity of this polyester. The occurrence of such effect is by no means surprising since most of homopolyesters made of isohexides are known to be unable to crystallize. ${ }^{44-46}$
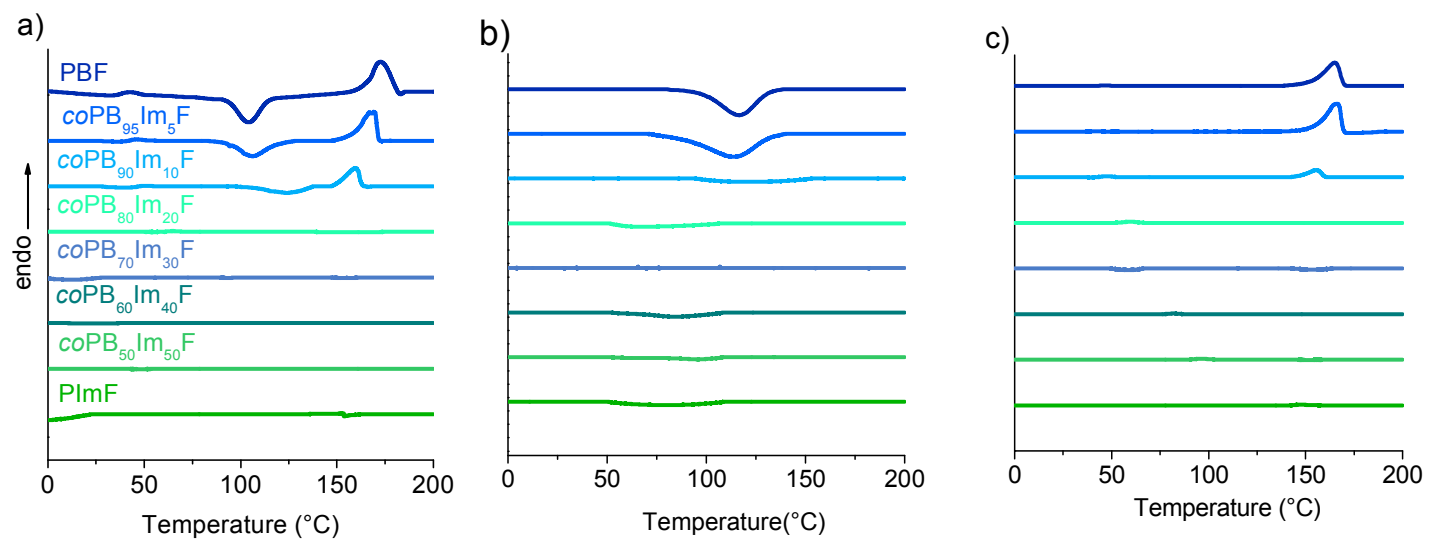

Figure 7. a) First heating, b) cooling, and c) second heating of $\operatorname{coPB}_{\mathrm{x}} \mid \mathrm{m}_{\mathrm{y}} \mathrm{F}$.

The crystallinity of $\operatorname{coPB}_{95} \mathrm{Im}_{5} \mathrm{~F}$ detected by $\mathrm{DSC}$ was firmly sustained by XRD analysis (Figure S6). The powder diffraction pattern recorded from this copolyester displayed discrete scattering that was similar in both spacing and intensity to that of PBF. The scattering showed by $\operatorname{coPB}_{90} \mathrm{Im}_{10} \mathrm{~F}$ was much poorer but still indicative of a slight crystallinity according to what was observed by DSC. Additionally, the characteristic grainy texture displayed by PBF films when they are observed by POM was also present in the films of these two copolyesters (Figure S7). It can be concluded from these observations therefore that both $\operatorname{coPB}_{95} \operatorname{Im}_{5} \mathrm{~F}$ and ${ }^{\circ} \mathrm{OPB} B_{90} \operatorname{lm}_{10} \mathrm{~F}$ are semicrystalline and that they crystallize sharing the crystal structure of PBF. The crystallization of copolyesters containing small amounts of one of their comonomers in the crystal lattice of the homopolymer made of the major comonomer is a well-known 
common fact. The phenomenon is understood by assuming that upon crystallization the minor comonomer is rejected to the amorphous phase and only homogeneous sequences made of the main comonomer are incorporated in the crystal phase. ${ }^{47-49}$ Since the capacity of $c o P B_{x} I_{y} F$ to crystallize is so severely restricted, the kinetics study addressed to quantify the influence of composition on crystallizability had to be restricted to the $\mathrm{PBF} / \mathrm{coPB}_{95} \mathrm{Im}_{5} \mathrm{~F}$ pair. The isothermal crystallization of these two polyesters was carried out at $146{ }^{\circ} \mathrm{C}$ and the evolution of crystallinity with time was compared. The typical sigmoidal curves resulting from these assays are plotted in Figure 8 , and the kinetic parameters estimated by application of the Avrami approach to the experimental data are given in Table 3. As it could anticipated, PBF and ${ }^{c o P B}{ }_{95} I_{5} \mathrm{~F}$ crystallized through a similar mechanism (their Avrami exponents are comparable) but the crystallization process is highly delayed for the copolyester $\left(t_{1 / 2}\right.$ is almost doubled).

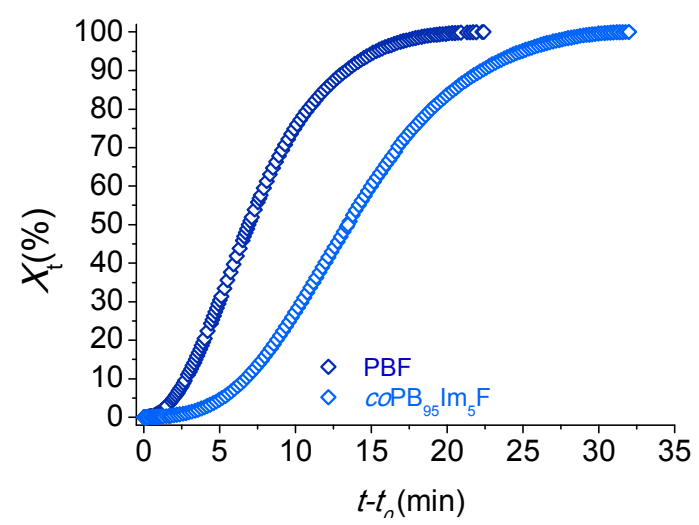

Figure 8. Relative crystallinity vs time in the isothermal crystallization of PBF and $c 0 P B_{95} I_{5} \mathrm{~F}$ at $146^{\circ} \mathrm{C}$.

The glass-transition temperature of the copolyesters was measured on the DSC heating traces registered from samples that were rapidly cooled from the melt. These traces showing the inflections indicative of glass-transition may be inspected in the SI file (Figure S8), and the $T_{g}$ values estimated therefrom are listed in Table 3 . It was found that the $T_{\mathrm{g}}$ of PBF appearing at $42^{\circ} \mathrm{C}$ raised up to $97^{\circ} \mathrm{C}$ as the content of the polymer in Im increased from 0 to $50 \%$-mole. Obviously, the replacement of the 
relatively flexible butylene unit by the much more rigid Im bicyclic structure reduced the chain mobility triggering a notable increase in $T_{g}$. The high stiffness of $\mathrm{Im}$ is clearly brought into evidence in the PImF homopolyester itself, which has a $T_{g}$ of $189^{\circ} \mathrm{C}$. The variation of $T_{\mathrm{g}}$ with the copolyester composition is plotted in Figure 9 where the experimentally observed values are compared with those predicted by the Fox and Gordon-Taylor equations. ${ }^{50,51}$ As it is largely expected from the amorphous nature of the $\operatorname{coPB}_{\mathrm{x}} \mathrm{Im} \mathrm{F}$, a good fit is attained with both equations as far as contents in $\mathrm{Im}$ are $20 \%$ and higher. The deviations detected for $\mathrm{PBF}, \operatorname{coPB}_{95} \mathrm{Im}_{5} \mathrm{~F}$ and $\mathrm{coPB}_{90} \mathrm{Im}_{10} \mathrm{~F}$ are likely due to the crystallinity present in these polyesters.

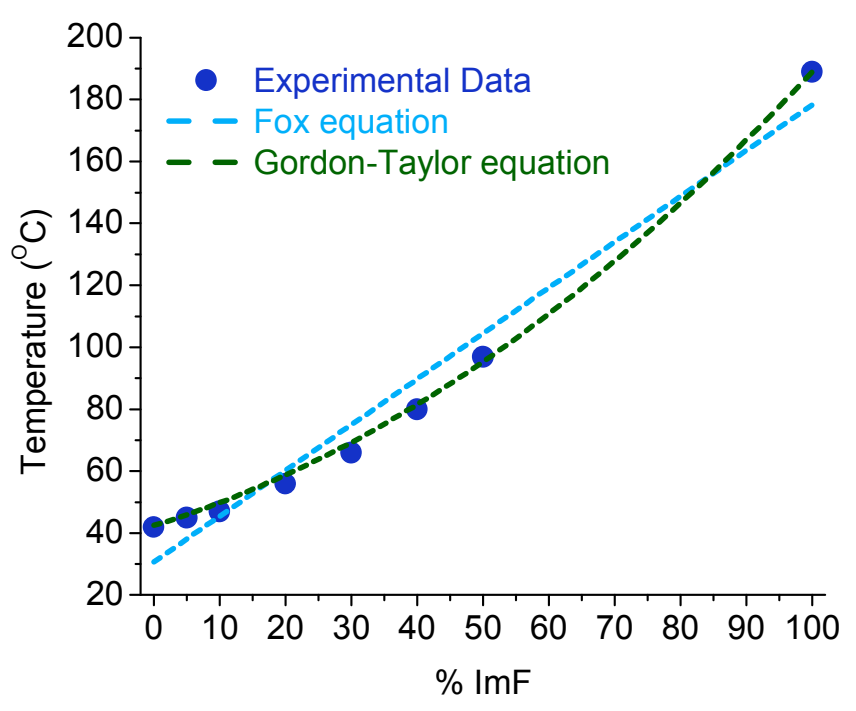

Figure 9. Variation of $T_{\mathrm{g}}$ with composition in the $\mathrm{COPB}_{\mathrm{x}} I \mathrm{~m}_{\mathrm{y}} \mathrm{F}$ series.

Hydrolytic and enzymatic degradation. Both hydrolytic degradation and

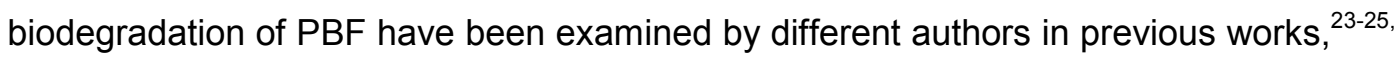
52,53 the which unanimously reported the high resistance of this polyester to be attacked by water. This is a behavior characteristic of aromatic polyesters that is commonly rationalized by taking into account the hydrophobicity and high $T_{\mathrm{g}}$ caused by the 
presence of the aromatic units. On the other hand, the incorporation of isohexide units in polyesters has been repeatedly reported to increase their sensitivity to water. ${ }^{34,36,54}$

The effect played by the presence of isomannide in the degradability of PBF has been examined in this work in a systematic manner. Both the decrease in sample weight and molecular weight during 30 days of incubation in a phosphate buffer at 7.4 with and without the assistance of porcine pancreas enzyme was monitored for $\mathrm{coPB}_{\mathrm{x}} \mathrm{Im} \mathrm{m}_{\mathrm{y}} \mathrm{F}$ copolyesters containing 30 and $40 \%$-mole of $\mathrm{Im}$ as well as for the PBF and PImF homopolyesters, and results are plotted in Figure 10. It is apparent in these plots

a)
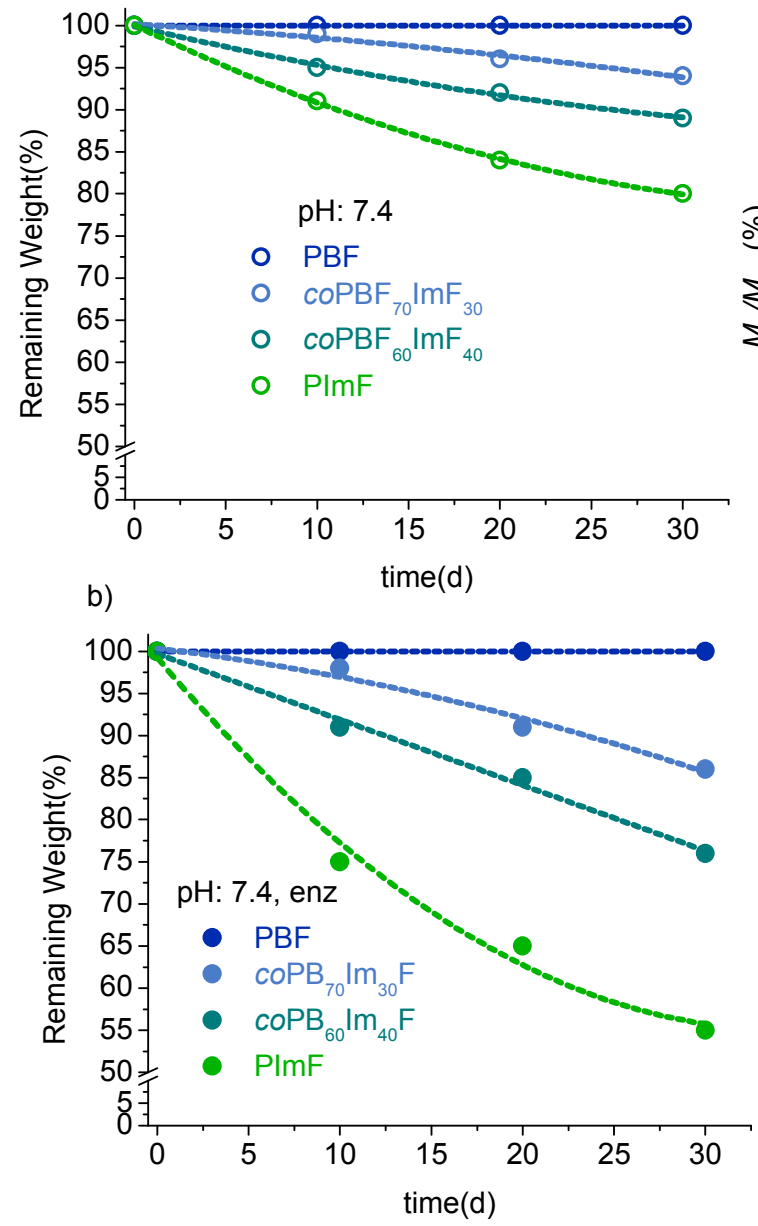

$\left.a^{\prime}\right)$
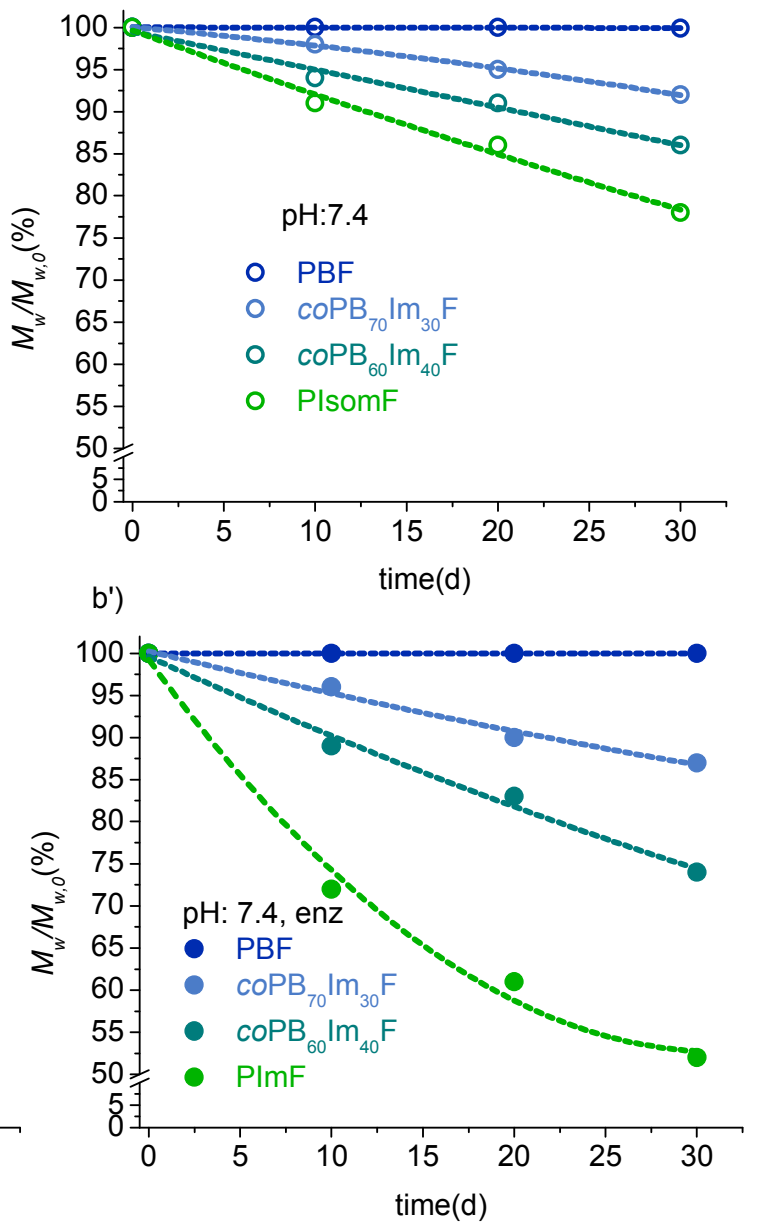

Figure 10. Hydrolytic (a and a') and enzymatic ( $b$ and b') degradation of $\operatorname{coPB}_{\mathrm{x}} \mathrm{Im} \mathrm{m}_{\mathrm{y}} \mathrm{F}$ upon incubation in water at $\mathrm{pH} 7.4$. 
that copolymerization enhances significantly the degradability of PBF. In fact, an essentially invariable function independent of time was obtained in the incubation of PBF for both sample weight and molecular weight, and either with or without enzyme added. On the contrary, PImF appears to be highly sensitive to hydrolysis undergoing around $20 \%$ of degradation after 30 days of incubation, a value that increase up to near $50 \%$ in the presence of porcine pancreas lipases. The positive response shown by this polyester to hydrolysis, and in particular when it is mediated by enzymes, is certainly amazing given its very high $T_{\mathrm{g}}\left(\sim 190^{\circ} \mathrm{C}\right)$, and brings into evidence the great sensitivity of Im-containing polyesters to biodegradation. In agreement with the behavior observed for the two reference homopolyesters, $\mathrm{COPB}_{70} \mathrm{Im}_{30} \mathrm{~F}$ and ${ }_{\text {CoPB60Im40F }}$ copolyesters showed a noticeable hydrolytic degradation at a rate that increased with the content in Im, and that was significantly enhanced in the presence of lipases.

\section{Conclusions}

Furanoate-based cyclic oligomers have been demonstrated in several previous reports to be useful monomers for ring opening polymerization and copolymerization. Cyclic oligomers of isomannide 2,5-furandicarboxylate could be successfully synthesized in this work for the first time. As it generally happens, a mixture of dimer, trimer and tetramer species, largely enriched in the dimer, was obtained. This oligomeric mixture was successfully copolymerized with cyclic butylene 2,5furandicarboxylate oligomers to render random butylene-co-isomannide copolyfuranoates with satisfactory molecular weights and compositions similar to those used for feeding. These novel copolyesters are greatly resistant to heat and they are amorphous except for extremely low contents in isomannide. The most outstanding feature of these Im-containing copolyesters is their high $T_{\mathrm{g}}$, which increases almost monotonically with the content in isomannide to reach a value near to $100{ }^{\circ} \mathrm{C}$ for a 50 \%-mole of composition. A second merit of these copolyesters is their apparent 
sensitivity to hydrolytic degradation whereras the homopolyester entirely made of butylene furanoate is essentially inert to water. Moreover the Im-containing copolyfuranoates become much more rapidly hydrolyzed when subjected to the action of lipases, a certainly amazing behavior given their relatively high $T_{\mathrm{g}}$. The overall conclusions that can be drawn from this work are: a) Polyfuranoates and copolyfuranoates containing isomannide may be prepared via ROP, which constitutes a large step forward the generalization of the ROP technique for the synthesis of furanoate-based polyesters. This methodology would be extensible to other isohexides provided that their cyclic oligofuranoates could be prepared. b) Polyfuranoates containing isomannide are shown to be fully bio-based copolyesters that are distinguished by being amorphous for a wide range of compositions, by having a high $T_{\mathrm{g}}$, and by displaying noticeable biodegradability.

\section{Acknowledgements}

Financial support for this research was afforded by MINECO with grants MAT2012-38044-CO3-03 and MAT-2016-77345-CO3-03. J.C. Morales-Huerta thanks to CONACYT (Mexico) for the Ph.D. grant awarded.

\section{References}

1 Brunelle J. Cyclic oligomer chemistry. J. Polym. Sci., Polym. Chem. 2007, 46, $1151-$ 1164.

2 Hodge, P. Entropically driven ring opening polymerization of strainless organic macrocycles. Chem. Rev. 2014, 114, 2278-2312.

3 Pang, K.; Kotek, R.; Tonelli, A. Review of conventional and novel polymerization processes for polyesters Prog. Polym. Sci. 2006, 31, 1009-1037.

4 Jerome, C.; Lecomte, P. Recent advances in the synthesis of aliphatic polyesters by ring-opening polymerization. Adv. Drug Deliv. Rev. 2008, 60, 1056-1076.

5 Dechy-Cabaret, O.; Martin-Vaca, B.; Bourissou, D. Controlled ring-opening polymerization of lactide and glycolide. Chem. Rev. 2004, 104, 6147-6176.

6 Labet, M.; Thielemans, W. Synthesis of polycaprolactone: a review. Chem. Soc. Rev. 2009, 38, 3484-3504. 
7 Pang, X.A.; Zhuang, X. L.; Tang, Z.H.; Chen, X.S. Polylactic acid (PLA): Research, development and industrialization. Biotech. J. 2010, 5, 1125-1136.

8 Duda A.; Kowalsky, A. Thermodynamics in kinetics of ring opening polymerization. Wiley-VCH Verlag, 2009.

9 Strandman, S.; Gautrot, J.E.; Zhu, X.X. Recent advances in entropy-driven ringopening polymerizations. Polym. Chem. 2011, 2, 791-799.

10 Sheirs, J.; Long, T.E. Modern Polyesters, Wiley, 2003.

11 Thomas, R.A.F.; Bordado, J.C.M.; Gomes, J.F.P. p-Xylene oxidation to terephthalic acid: a literature review oriented toward process optimization and development. Chem. Rev. 2013, 113, 7421-7469.

12 Liu, H.J.; Xu, Y.Z.; Zheng, Z.M.; Liu, D.H. 1,3 propanediol and its copolymers: research, development and industrialization. Biotech. J. 2010, 5, 1137-1148.

13 Rogers, M.E.; Long, T.E.; Synthetic methods in step-growth polymers. Wiley, 2003. 14 Brunelle, D.J. Ring opening of macrocycles. Abstracts ACS 1996, 212, 366-POLY. 15 Brunelle, D.J.; Bradt, J.E.; Serth-Guzzo, J.; Takekoshi, T.; Evans, T.L.; Pearce, E. J.; Wilson, P.R. Semicrystalline polymers via ring opening polymerization: preparation and polymerization of alkylene phthalate cyclic oligomers. Macromolecules 1998, 31 , 4782-4790.

16 Hubbard, P.; Brittain, W.J. Synthesis and ring-opening polymerization of poly(alkylene 2,6-naphthalenedicarboxylate) cyclic oligomers. Macromolecules 1996, 29, 8304-8307.

17 Jiang, H.; Chen, T.; Xu, J. Synthesis, structure, and ring-opening polymerization of macrocyclic aromatic esters: A new route to high-performance polyarylates.

Macromolecules 1997, 30, 2839-2842.

18 Kameyama, A.; Ide, T.; Nishikubo, T. Solid phase ring-opening polymerization of macrocyclic S-Aryl thioesters containing terephthaloyl structure. High. Perform. Polym. 2003, 15, 207-218.

19 González-Vidal, N.; Martínez de Ilarduya, A.; Herrera, V.; Muñoz-Guerra, S. Poly(hexamethylene terephthalate-co-caprolactone) copolyesters obtained by ring opening polymerization. Macromolecules 2008, 41, 4136-4146.

20 Giammanco, G.; Martínez de llarduya, A.; Alla, A.; Muñoz-Guerra, S.; Hydrolyzable aromatic copolyesters of $p$-dioxanone. Biomacromolecules 2010, 11, 2512-2520.

21 Pfister, D.; Storti, G.; Tancini, F.; Costa, L.I. Morbidelli, M. Synthesis and ring opening polymerization of cyclic butylene 2,5-furandicarboxylate Macromol. Chem. Phys. 2015, 21, 2141-2146.

22 Morales-Huerta, J.C.; Martínez de llarduya, A.; Muñoz-Guerra, S. Poly(alkylene 2,5furandicarboxylate) (PEF and PBF) by ring opening polymerization. Polymer 2016, 87, 148-158.

23 Morales-Huerta, J.C.; Martínez de Ilarduya, A.; Muñoz-Guerra, S. Sustainable aromatic copolyesters via ring opening polymerization: poly(butylene 2,5-

furandicarboxylate-co-terephthalate)s. ACS Sustain. Chem. Eng. 2016, 4, 4965-4973. 
24 Morales-Huerta, J.C.; Martínez de Ilarduya, A.; Muñoz-Guerra, S. Fully bio-based aromatic-aliphatic copolyesters: poly(butylene furandicarboxylate-co-succinate)s obtained by ring opening polymerization. Polym. Chem. 2017, 8, 748-760.

25 Morales-Huerta, J.C.; Martínez de Ilarduya, A.; Muñoz-Guerra, S. Blocky poly ( $\varepsilon-$ caprolactone-co-butylene 2,5-furandicarboxylate) copolyesters via enzymatic ring opening polymerization. J. Polym. Sci., Polym. Chem. 2018, 56, 290-299.

26 Sousa, A.F.; Vilela, C.; Fonseca A.C.; Matos, M.; Freire, C.S.R; Gruter, G.-J.M.; Coelho, J.F.J; Silvestre, A.J.D. Biobased polyesters and other polymers from 2,5furandicarboxylic acid: a tribute to furan excellency. Polym. Chem. 2015, 6, 59615983.

$27 \mathrm{Ma}$, J.; Yu, X.; Xu. J.; Pang, Y. Synthesis and crystallinity of poly(butylene 2,5furandicarboxylate). Polymer, 2012, 53, 4145-4151.

28 Zhu, J.; Cai, J. ; Xie, W.; Chen, P.-H.; Gazzano, M.; Scandola, M.; Gross, R.A. Poly(butylene 2,5-furandicarboxylate), a bio-based alternative to PBT: Synthesis, physical properties, and crystal structure. Macromolecules 2013, 46, 796-804.

29 Papageorgiou, G.Z.; Papageorgiou, D.G.; Terzopoulou, Z.; Bikiaris, D.N. Production of bio-based 2,5-furandicarboxylate polyesters: Recent progress and critical aspects in their synthesis and thermal properties. Eur. Polym. J. 2016, 83, 202-209.

30 Soccio, M.; Martínez-Tong, D.E.; Alegría, A.; Munari, A.; Lotti, N. Molecular dynamics of fully biobased poly(butylene 2,5 -furanoate) as revealed by broadband dielectric spectroscopy. Polymer, 2017, 128, 24-30.

31 Fenouillot, F.; Rousseau, A.; Colomines, G.; Saint-Loup, R.; Pascault, J.P. Polymers from renewable 1,4:3,6-dianhydrohexitols (isosorbide, isomannide and isoidide): A review. Prog. Polym. Sci. 2010, 35, 578-622.

32 Van Es, D.S. Rigid Biobased Building Blocks. J Renew. Mat. 2013,1, 61-72.

33 Muñoz-Guerra, S.; Lavilla, C.; Japu, C.; Martínez de llarduya, A. Renewable terephthalate polyesters from carbohydrate-based bicyclic monomers. Green Chem. 2014, 16, 1716-1739.

34 Kricheldorf H.R.; Behnken G.; Sell M. Influence of isosorbide on glass-transition temperature and crystallinity of poly(butylene terephthalate). J Macromol Sci Part A Pure Appl Chem. 2007, 44, 679-684.

35 Kim, T.; Koo, J.M.; Ryu, M.H.; Jeon, H.; Kim, S.M.; Park, S.A.; Oh, D.X.; Park, J.; Hwang, S.Y. Sustainable terpolyesters of high $T_{g}$ based on bioheterocyclic of dimethyl furan 2,5-dicarboxylate and isosorbide. 2017, 132, 122-132.

36 Okada, M.; Tachikawa, K., Aoi, K. Biodegradable polymers based on renewable resources: polyesters composed of 1,4:3,6-dianhydrohexitol and aliphatic dicarboxylic acid units J. Polym. Sci., Polym. Chem. 1996, 62, 2257-2265.

37 Rose, M.; Palkovits, R. Isosorbide as a renewable platform chemical for versatile applications. ChemSusChem 2012, 5, 167-176.

38 Janvier, M.; Moebs-Sancez, S.; Popowycz, F. Bio-based amides from renewable isosorbide by a direct and atom-economic boric acid amidation methodology. Eur. J. Org. Chem. 2016, 13, 2308-2318. 
39. Kricheldorf, H.R.; Chatti, S.; Schwarz, G.;Krüger, R.-P. Macrocycles 27: Cyclic aliphatic polyesters of isosorbide. J. Polym. Sci., Polym. Chem. 2003, 41, 3414-3424.

40 Chatti, S.; Schwarz, G.; Kricheldorf, H.R. Cyclic and noncyclic polycarbonates of isosorbide (1,4:3,6-dianhydro-D-glucitol). Macromolecules 2006, 39, 9064-9070.

41 Storbeck R.; Ballauf, M. Synthesis and properties of polyesters based on 2,5furandicarboxylic acid and 1,4:3,6-dianhydrohexitols. Polymer, 1993, 34, 5003-5006.

42 Souza, A. F.; Coelho, J. F. J.; Silvestre, A. J. D. Renewable-based poly(ether)ester)s from 2,5-furandicarboxylic acid. Polymer 2016, 98, 129-135.

43 Randall, J.C. In Polymer Sequence determination, New York. 1977, 42-62.

44 Zhang, F.C.; Wang, Q.X.; Wang, L.P.; Bai, Y.P. Implementing plant-derived isosorbide and isomannide as comonomers for polyester synthesis: Effects of crystallization properties on optical properties. J. App. Polym Sci. 2017, 134, 45444.

45 Majdoub, M,; Loupy, A.; Fleche, G. New polyethers and polyesters from isosorbide: synthesis and characterization. Eur. Polym. J. 1994, 30, 1431-1437.

46. Kricheldorf, H.R.; Behnken, G.; Sell, M. Influence of isosorbide on glass-transition temperature and crystallinity of poly(butylene terephthalate). J. Macromol. Sci. Part A Pure Appl. Chem. 2007, 44, 679-684.

47 Takeda, H.; Ehara, M.; Sakai, Y.; Choi, S.C. Thermal crystallization of poly(ethylene-terephthalate) and its copolyesters- effect of degree of polymerization and copolymerized components. Text. Res. J. 1991, 61, 429-432.

48 Sakaguchi, Y.; Okamoto, M. Tanaka, I. Modification of crystallization of poly(ethylene-terephthalate) by copolymerization with arylate units. 1. Preparation and isothermal crystallization of 4,4'-biphenol-containing copolymers. Macromolecules 1995, 28, 6155-6160.

49 Ciulik, C.; Safari, M.; Martínez de llarduya, A.; Morales-Huerta, J. C.; Iturrospe, A.; Arbe, A.; Müller, A. J.; Muñoz-Guerra, S. Poly(butylene succinate-ran-e-caprolactone) copolyesters: Enzymatic synthesis and crystalline isodimorphic carácter. Eur. Polym. J. 2017, 95, 795-808.

50 Fox, T. G. Influence of diluent and of copolymer composition on the glass transition temperature of a polymer system. Bull. Am. Phys. Soc. 1956, 1, 123-135.

51 Gordon, M.; Taylor, J.S. Ideal copolymers and the $2^{\text {nd }}$-order transitions of synthetic rubbers. 1. Non-crystalline copolymers. J. Appl. Chem. 1952, 2, 493-500.

52 Zhou W.; Wang, X.; Yang, B.; Xu, Y.; Zhang, W.; Zhang, Y.; Ji, J. Synthesis, physical properties and enzymatic degradation of bio-based poly(butylene adipate-cobutylene furandicarboxylate) copolyesters. Polym. Degrad. Stab. 2013, 98, 2177-2183.

$53 \mathrm{Bu}$, W.; Xu, Y.; Bu, Z.; Wu, L.; Li, B.-G., Dubois, P. Biobased poly(butylene 2,5furandicarboxylate) and poly(butylene adipate-co-butylene 2,5-furandicarboxylate)s : From synthesis using highly purified 2,5-furandicarboxylic acid to thermo-mechanical properties. Polymer 2014, 55, 3648-3655.

54. Chatti, S.; Weidner, S.M.; Fildier, A.; Kricheldorf, H. R. Copolyesters of isosorbide, succinic acid and terephthalic acids: Biodegradable, high $T_{g}$ engineering plastics. J. Polym. Sci., Polym. Chem. 2013, 51, 2464-2471. 